\title{
Estratégias Construtivas para a Configuração do Produto de Moda
}

\author{
Construction strategies for the fashion product configuration
}

\author{
SOUZA, Patrícia de Mello; Mestre; Universidade Estadual de Londrina; \\ Doutoranda PPGDesign, Faculdade de Arquitetura, Artes e Comunicação - UNESP \\ patmel@sercomtel.com.br \\ MENEZES, Marizilda dos Santos; Doutora; Faculdade de Arquitetura, Artes e \\ Comunicação - UNESP \\ marizil@faac.unesp.br
}

\begin{abstract}
Resumo
O presente artigo trata das possibilidades e estratégias de construção para o desenvolvimento do produto de moda. Investiga-se a aplicação de diferentes recursos construtivos aos materiais têxteis de mesma composição e caimento, estabelecendo, para tanto, parâmetros de similaridade formal. $O$ processo de concepção dos produtos é conduzido pela expressão tridimensional, o que permite que as etapas de criação e

materialização aconteçam de modo simultâneo. Técnicas de modelagem tridimensional viabilizam as construções que são estruturadas pelos seguintes recursos investigados: intervenção na superfície têxtil, inserção de elementos independentes e diferentes resoluções de confecção. Os resultados obtidos instigam à reflexão acerca dos processos envolvidos.
\end{abstract}

Palavras Chave: Design de moda. Modelagem. Recursos construtivos.

\begin{abstract}
This article approaches possibilities and strategies of building to development of fashion product. It investigates the application of different constructive resources of textile materials of same composition and trim, establishing for this parameters of formal similarity. The conception of products process is conducted by three-dimensional expression, which allows the steps for creating and delivering happen simultaneously. Three-dimensional modeling techniques enable the buildings that are structured by the following features investigated: intervention in the textile surface, insertion of independent elements, and different confection resolutions. The results instigate reflection about the processes involved.
\end{abstract}

Keywords: Fashion design. Modeling. Constructive resources.

\section{Introdução}

No desenvolvimento do produto de moda, o material têxtil é projetado para delimitar um espaço em torno do corpo, configurando silhuetas que se apresentam segundo características de forma, que definem linhas e volumes, e mantém com o corpo/suporte uma relação de proximidade ou de distanciamento. Existe uma estreita relação entre o material proposto e a silhueta pretendida. Em geral, um material pesado e encorpado não se prestaria a uma silhueta aderente, da mesma forma que um tecido leve e fluido não serviria a uma silhueta trapezóide com linha de contorno rígida - salvo nos casos em que elementos construtivos são 
Estratégias Construtivas para a Configuração do Produto de Moda incorporados ao têxtil, fundindo-se a ele ou intervindo e qualificando sua superfície. Neste sentido direciona-se o presente trabalho.

Trata-se da apresentação e discussão de parte da pesquisa que está sendo realizada para fundamentar uma tese de doutorado em design, que encontra-se em fase de desenvolvimento. Em meio aos registros, relata-se uma atividade projetual desenvolvida com os alunos do terceiro ano do curso de Design de Moda da UEL, na disciplina Laboratório da Forma Avançada, ministrada pela autora, que contribui para ilustrar de forma clara, aspectos relevantes do estudo. Com o intuito de investigar como se processa a construção dos produtos com materiais têxteis de propriedades distintas, bem como, por outro lado, explorar a aplicação de diferentes recursos construtivos ao mesmo material têxtil, propõe-se o desenvolvimento de silhuetas geométricas com o uso do algodão cru, cuja composição é $100 \%$ algodão, e do voil, $100 \%$ poliéster.

Apesar das silhuetas, em geral, virem representadas nos planos frontal ou dorsal, conferir aos planos laterais a mesma importância dos demais, é um recurso válido para a obtenção de inovação formal. Além disso, não se pode desvincular o pensamento construtivo das questões que influenciam e determinam o resultado estético dos produtos. Tal condição justifica o emprego de técnicas de modelagem tridimensional - moulage - para viabilizar os processos de construção aqui registrados, nos quais as etapas de criação e materialização se fundem.

Os seguintes recursos construtivos são investigados: intervenção na superfície têxtil, inserção de estruturas ou elementos independentes e diferentes resoluções de confecção, entre elas, a articulação de planos.

\section{A configuração do produto}

A silhueta é a configuração morfológica e volumétrica ao redor do corpo, que define seu contorno, também chamada de formato ou shape. Saltzman (2004) afirma que do ponto de vista morfológico o vestuário pode ser obtido de três formas distintas: pela união de planos têxteis, seja por processo de costura ou inserção de elementos conectivos; pelo processo integrado e concomitante de tecelagem e montagem do produto; ou simplesmente pelo envolver o corpo.

Ao pensar na estrutura e configuração do material têxtil sobre a anatomia corpórea, Souza (2006) eSaltzman (2008) concordam que a sustentação éaspecto relevante, independente da maneira como se cobre esse corpo. Ela é atributo da prática construtiva e se processa de várias formas: naturalmente, pelo apoio da vestimenta nas partes extremas superiores do corpo como ombros e cabeça; pelo traçado da modelagem que retraça a anatomia corpórea e encaixa saliências e reentrâncias de modo a priorizar regiões do corpo que favorecem o apoio; pelas próprias características do tecido que promovem a aderência ao corpo; pela contribuição dos mecanismos de abertura e fechamento; entre outros, que serão tratados adiante na abordagem dos recursos construtivos.

A configuração da silhueta, portanto, depende das características dos tecidos e das soluções construtivas aplicadas, que conferem sustentação aos produtos. Babados, nervuras, drapeados, franzidos, recortes, entre outros, dependendo de como são projetados, constituemse importantes elementos de construção. O próprio material têxtil pode contemplar a estrutura pretendida, seja por suas características específicas de peso e caimento ou por intervenções aplicadas em sua superfície, neste caso, tornando-o autoportante. 
Para Souza e Menezes (2010), estes elementos que permitem estruturar a forma do produto - utilizados de modo isolado ou combinados entre si - podem ser denominados de recursos construtivos, na medida em que promovem sustentação e ajustamento ou configuram volumes que garantem o equilíbrio requerido.

Neste sentido, alguns autores pesquisam diferentes métodos de gerar forma que contribuem na estruturação dos produtos.

Vysoviti (2008), por exemplo, explora o potencial das dobraduras de papel: seus modelos explicativos demonstram o procedimento passo a passo da transformação de uma superfície plana em uma tridimensional. Ao invés de descrever as características formais do resultado final, o foco está no processo, isto é, na descrição da origem e da evolução do desenvolvimento a partir das dobraduras, para que a experiência possa ser compreendida por outros.

Segundo Hodge (2008), o uso da geometria para gerar forma é outra estratégia explorada: utilizam-se estruturas simples tais como círculos, quadrados e elipses; assim como mais complexas, que envolvem torção. Quando a peça está envolvida no corpo, sua forma se altera e a geometria inicial que a gerou, muitas vezes torna-se invisível.

A manipulação dos diferentes materiais têxteis combinados às distintas soluções construtivas possibilita modelar e recriar a estrutura corpórea conforme desejado, para que o produto mantenha-se próximo ou distante do corpo. Souza (2006) reafirma esta questão, ao garantir que são infinitas as possibilidades formais, mas que a conformação da vestimenta está atrelada à natureza dos materiais utilizados e às soluções estruturais que permitem, definindo o modo como se articulam ao redor do corpo.

Para Aldrich (2007) existe uma estreita relação entre o corte da vestimenta e o potencial do tecido, isto é, não basta o conhecimento técnico a respeito dos materiais: é preciso conhecer o seu comportamento em diferentes propostas de produtos. Trata-se de proceder à apreciação estética dos têxteis, o que envolve aspectos visuais e táteis, para perceber suas possibilidades estruturais e as formas determinadas por sua utilização.

É pertinente afirmar, que o vestuário estabelece um espaço para conter o corpo. Esta espacialidade também é determinada pela estrutura anatômica e mobilidade corporal, e constitui-se em volumes que aderem, aproximam-se e se afastam do corpo ou ainda se projetam além de seus limites. Segundo Saltzman (2004), para viabilizar tal proximidade ou distanciamento, existem os seguintes recursos:

- intervir na superfície têxtil: produzir a movimentação do tecido para facilitar sua adaptação à anatomia sem necessidade de recortes ou costuras - como no caso de drapeados, plissados ou torções; ou outros tipos de intervenção que possam conferir tridimensionalidade às superfícies têxteis;

-inserir estruturas independentes, como por exemplo, um arame, uma barbatana;

- traçar diferentes resoluções de confecção: inserir pences, pregas, franzidos, entre outros; ou articular os planos resultantes do corte dos tecidos, seja de forma fixa ou removível.

É fato que estas intervenções se materializam, inicialmente, por intermédio da modelagem, que vai dar forma à matéria-prima, transformando-a em produto. Como afirma Cross (2007), a modelagem é a linguagem do design.

A integração de todos estes aspectos - materiais têxteis, recursos de construção e espacialidade - que estão envolvidos na configuração dos produtos, requer uma tomada de decisão, que implica em determinações estéticas, funcionais e ergonômicas.

Projética Revista Científica de Design I Universidade Estadual de Londrina I V.2 I N.1 I Junho 2011 
Estratégias Construtivas para a Configuração do Produto de Moda

Neste contexto a investigação é facilitada e torna-se mais eficaz quando o processo construtivo é conduzido pela expressão tridimensional, onde as etapas de criação e materialização se fundem, isto é, quando o desenvolvimento se processa por meio da aplicação de técnicas de modelagem tridimensional. Castro (2010) define esta técnica de um modo peculiar: para a autora, trata-se de uma forma contínua de desenvolvimento criativo de moldes. Elaborados inicialmente sobre um busto de costura, ou manequim técnico, para obtenção de um modelo específico, posteriormente são transferidos para o papel, envolvendo um processo de experimentação caracterizado por aceitações e rejeições no qual cada ação pode ser imediatamente visualizada. Martin (2009) acrescenta que apesar de ser um processo artesanal, é uma técnica que permite a criação de volumes atípicos que dificilmente seriam obtidos de forma unidimensional.

\section{Modelagem tridimensional e construção}

A modelagem tridimensional, por suas características intrínsecas, é um instrumento que auxilia na verificação e análise prática dos dados da pesquisa. Os seguintes aspectos que envolvem ou são propiciados pela referida técnica ${ }^{1}$ são considerados relevantes no sentido de facilitar a construção e análise dos produtos: a tridimensionalidade do corpo/ suporte; a experimentação e visualização simultâneas objetivadas pelo fazer; a exploração das possibilidades de configuração e emprego de materiais; a avaliação contínua ao longo do processo.

A primeira questão que se apresenta na prática da modelagem tridimensional é o conhecimento da estrutura do corpo, condição essencial para a adequação dimensional do produto. A vivência da tridimensionalidade, que neste caso utiliza como suporte um manequim técnico na escala 1:2, permite que tal conhecimento se realize integralmente de forma a possibilitar a visualização de frente, de lado e de costas. Assim, propicia-se a educação do olhar, desenvolve-se a percepção da escala, bem como permite-se apreendê-la pelo fazer.

A aquisição de domínio sobre as proporções do corpo é progressivamente alcançada por meio da vivência do processo. Esse conhecimento vai propiciando uma análise cada vez mais criteriosa a respeito da conformidade da estrutura corpórea com a vestimenta, para aferir o espaço necessário entre o corpo e o produto, isto é, os aspectos de folga determinantes da silhueta.

Pela ação escultórica sobre o suporte para a materialização da idéia, o produto que se concretiza na medida em que avança o processo, é resultado de uma apropriação gradativa dos elementos da linguagem tridimensional - linhas, planos, volumes, proporções, texturas entre outros - que se fazem presentes na definição da configuração do produto. No que se refere à exploração das possibilidades materiais exeqüíveis em sua relação com o modelo e o suporte, a técnica permite constatar a grande importância da análise ser realizada de forma prática, pois a verificação é feita com o produto vestido no manequim, que aponta o material têxtil como determinante da silhueta e do caimento da peça.

Ao usar qualquer método, confirma Aldrich (2007), a consideração primordial deve ser o efeito produzido pelo tecido, visto em relação ao usuário final do produto, e sua forma no corpo em movimento.

A vivência do processo é dinâmica, envolvendo questionamentos e buscas constantes por novas soluções para viabilizar a materialização do produto: organiza-se e configura-se a forma esboçada, que vai sendo avaliada de forma contínua, ao mesmo tempo em que se 
Patrícia de Mello Souza; Marizilda dos Santos Menezes

desenvolve a familiaridade com o suporte, condição essencial para a obtenção de composições integradas.

O desenvolvimento do produto por meio da aplicação de técnicas de modelagem tridimensional, efetivamente permite a avaliação imediata dos aspectos abordados na construção, o que se realiza integralmente tão logo se conclui a configuração sobre o corpo/ suporte, portanto, em intervalo de tempo relativamente curto, tendo em vista a multiplicidade de elementos envolvidos e as contribuições positivas deste resultado para o processo.

\section{A atividade projetual}

Como forma de investigar a aplicação prática de diferentes recursos de construção a materiais têxteis específicos para definir quais são os elementos estruturantes e de que forma são utilizados, propõe-se a seguinte situação-problema: três silhuetas geométricas confeccionadas em algodão cru - um retângulo, um círculo e um trapézio, devem ser reproduzidas no que se refere às suas dimensões e proporções, utilizando o voil e, posteriormente, a mistura do voil com o algodão. A proposta define que os resultados obtidos devem ser avaliados considerando as silhuetas vestidas no manequim, portanto, não se trata de reproduzir o mesmo molde plano, mas sim, de explorar e verificar o comportamento dos tecidos, e de aplicar neles, elementos ou recursos capazes de estruturá-los o suficiente para conferir similaridade formal em situação de uso.

Inicialmente as três silhuetas são construídas de forma coletiva: suas dimensões e proporções são previamente discutidas pela turma de 20 alunos e em seguida planejadas e confeccionadas em escala 1:2 nas formas geométricas do retângulo, trapézio e círculo, constituindo-se bases de referência para as demais construções.

A partir daí, a turma é dividida em duplas e forma dez grupos. Cada dupla escolhe uma única figura geométrica para ser reproduzida duas vezes - uma silhueta configurada em voil e outra que mistura o voil e o algodão - ambas mantendo as dimensões da base.

Para estruturar as silhuetas os alunos devem aplicar recursos diferentes em cada uma, selecionados entre os seguintes:

• intervenção na superfície têxtil;

-inserção de estruturas ou elementos independentes ;

- diferentes resoluções de confecção:

- pregas, nervuras, franzidos, entre outros, desde que façam uso da costura;

-articulação de planos - diferentes composições de planos fixos ou removíveis.

Assim sendo, entre as dez propostas, são contempladas várias silhuetas retangulares, trapezoidais e circulares, estruturadas com variada gama de recursos, resultando em rico e diversificado material para a pesquisa. É relevante informar que este é um exercício projetual que não tem o objetivo de desenvolver produtos do vestuário, mas sim, de evoluir o pensamento construtivo.

Durante o desenvolvimento das silhuetas os alunos fazem o registro escrito e fotográfico do processo, além de pesquisa teórica que acompanha e fundamenta a atividade prática. Tais registros permitem a elaboração de artigos que foram submetidos ao VII Colóquio de Moda; e a organização e montagem de uma exposição ${ }^{2}$ dos projetos realizada na UEL que pode ser conferida no link.abaixo.

Projética Revista Científica de Design I Universidade Estadual de Londrina I V.2 I N.1 I Junho 2011 
Estratégias Construtivas para a Configuração do Produto de Moda

Os relatos das observações coletadas não são apresentados aqui na sua totalidade, mas sim, a seleção do que foi considerado relevante para ilustrar e discutir aspectos cruciais da pesquisa.

\section{Intervenção na superfície têxtil}

Trata-se da manipulação do material têxtil para conferir tridimensionalidade a sua superfície ou para produzir nele uma movimentação capaz de facilitar a acomodação ao corpo, em ambas as situações, sem a inserção de costuras. A intervenção pode ser inicialmente realizada em toda a superfície do material para depois aplicá-lo, já estruturado, no desenvolvimento do produto ou, por outro lado, pode ser concebida e elaborada com o material sobre o próprio suporte, neste caso, o manequim técnico, tendo a estrutura corporal com suas saliências e reentrâncias como um determinante para a criação.

No produto mostrado na figura 1, concebido pelo aluno Túlio Souza Costa, o voil, material têxtil composto de $100 \%$ poliéster, é submetido à temperatura de aproximadamente $200^{\circ} \mathrm{C}$ por 20 minutos, em forno doméstico, como forma de obter a fixação das interferências aplicadas, resultante de processo de manipulação anterior à etapa do aquecimento.



Figura 1- Exemplo de intervenção na superfície têxtil

Fonte: Própria (2011)

A tridimensionalidade da superfície é conseguida pelo uso de várias capas de botão de metal de tamanhos diferentes, envolvidas uma a uma pelo tecido, e amarradas com barbante fino, dispostas aleatoriamente por toda a extensão do material têxtil e, em seguida, levada ao forno. Cabe ressaltar que o processo não foi iniciado com esta intenção. Na fase de exploração do material o aluno percebeu que friccionando o tecido em superfícies ásperas e rígidas, como por exemplo, a quina de uma mesa de madeira, conseguia que o entrelaçamento do fios se desestruturasse, causando, não só pequenas rupturas, mas também a possibilidade de franzir, puxando os fios rompidos. Estas intervenções geram relevante efeito visual, semelhante ao que poderia ser obtido, por exemplo, com a inserção de lastex. O produto reproduz a silhueta retangular.

Projética Revista Científica de Design I Universidade Estadual de Londrina I V.2 I N.1 I Junho 2011 


\section{Inserção de estruturas independentes}

Trata-se de inserir elementos que aplicados ao material têxtil possam estruturá-lo, ou mesmo, gerar estruturas volumosas. Em geral, os aviamentos se prestam a esta finalidade. Entretelas, barbatanas, elásticos, cordões, botões, entre tantos outros, embora de maneiras distintas, cumprem a função requerida, desde que aplicados da forma adequada.

Para reproduzir a silhueta circular de referência, mostrada na figura 2, os três produtos descritos abaixo apresentam diferentes soluções construtivas e utilizam os elementos estruturantes de forma diversa.

As alunas lana Uliana Perez e Jéssica Maria Dainezi Roncatti empregam o voil para desenvolver a silhueta ilustrada na figura 3. No início pretendiam fazer uso da entretela, mas nas experimentações mostrou-se inadequada, por interferir no resultado estético e por comprometer os aspectos de transparência e leveza do voil, características específicas que gostariam de manter. Após novos testes, também descartaram a barbatana, por não proporcionar a sustentação necessária. Dando continuidade ao processo exploratório perceberam que o arame deveria ser o elemento estruturante para a obtenção do resultado esperado: uma estrutura composta de três círculos de sustentação, que alterna faces retas e curvas na parte inferior, e traz aberturas para a cava, na superior. O formato apresenta similaridade e coerência com as dimensões da silhueta circular sem, no entanto, reproduzir de forma idêntica a sua estrutura.

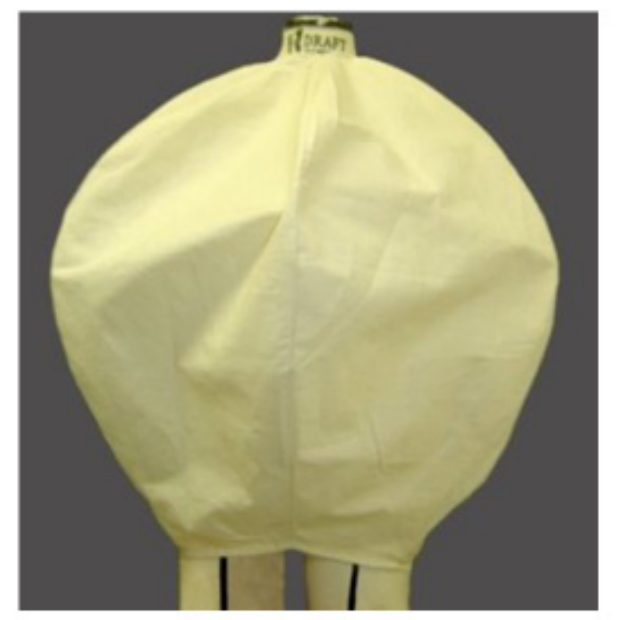

Figura 2- Silhueta circular de referência Fonte: Própria (2011)

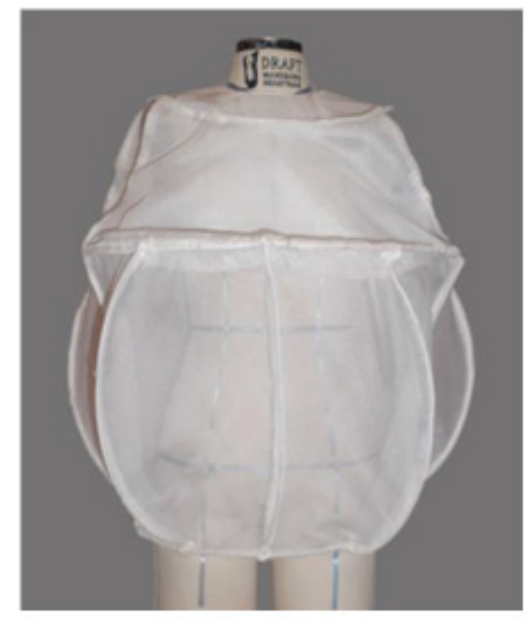

Figura 3- Exemplo de inserção de elementos independentes

Fonte: Própria (2011)

Na figura 4, a proposta concebida pelas alunas Betina Grosser Martins e lakyma Rejane Silva Lima, integra o algodão e o voil, na busca do equilíbrio da gramatura destes materiais por meio da inserção de um elemento estruturante, neste caso, a entretela. Na elaboração do produto, os dois tecidos são entretelados e dispostos de modo intercalado - como um tabuleiro de xadrez - para equilibrar o peso da estrutura. A união das várias partes se realiza por meio de costuras: ao costurar as duas lâminas, uma de algodão e outra de voil, geram-se arestas rígidas, responsáveis por conferir ao produto a silhueta circular. Uma prega traseira é inserida para reduzir parte do volume localizado, prevendo uma possível adaptação futura ao uso, uma vez que a amplitude excessiva poderia limitar os movimentos do corpo.

Projética Revista Científica de Design I Universidade Estadual de Londrina I V.2 I N.1 I Junho 2011 


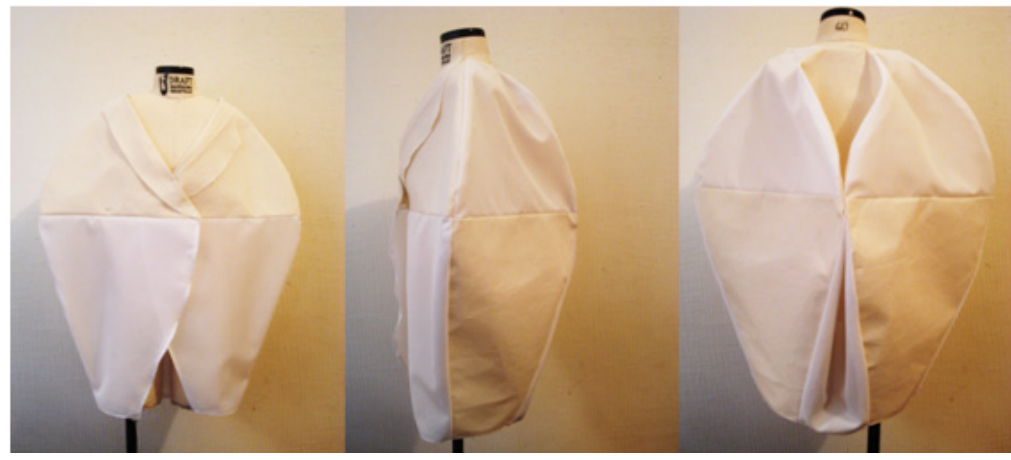

Figura 4- Exemplo de inserção de elementos independentes

Fonte: Própria (2011)

A proposta das alunas Timeni Andrade Gonçalves e Thaina de Oliveira Gonçalves é viabilizada pela inserção de barbatanas e elástico que conferem sustentação ao produto, juntamente com a sobreposição - solução construtiva encontrada. A figura 5 ilustra o esquema de construção e o resultado obtido.


Figura 5- Exemplo de inserção de elementos independentes

Fonte: Própria (2011)

Na base interna de algodão são inseridas as barbatanas, dispostas no tecido em intervalos iguais. Durante a experimentação sobre o manequim as alunas perceberam a necessidade de um outro elemento capaz de exercer pressão nas extremidades da estrutura para que ela se assemelhasse à silhueta circular de referência. Optou-se, então, pela aplicação do elástico nas duas extremidades, o que possibilitou que o produto assumisse o formato desejado. Em seguida foi utilizado o voil para desenvolver a parte externa do produto, aquela que sobrepõe a base. A intervenção na superfície do material por meio da aplicação do lastex, costurado conforme o esquema da figura 5 contribuiu para a geração de volume e a estruturação do têxtil, evidenciando a silhueta circular proposta.

Resoluções de confecção

Trata-se de aplicar ao material têxtil, pences, pregas, franzidos, nervuras, recortes entre tantos outros recursos, possibilitados pelo emprego da costura. Cabe ressaltar a a relevância dos recortes, condição acertadamente denominada por Saltzman (2004) de articulação de planos. Cada uma das várias partes integrantes da modelagem pode ser chamada de plano, que unidos dão origem à vestimenta e conferem volume, dependendo do formato em que são cortados e da maneira como se articulam.

Para construir a silhueta retangular mostrada na figura 6, a aluna Yara da Silva Santana utiliza pregas, nervuras, sobreposição e a estratégia de intercalar os materiais - no caso, algodão cru e voil - para equilibrar o peso da estrutura. 


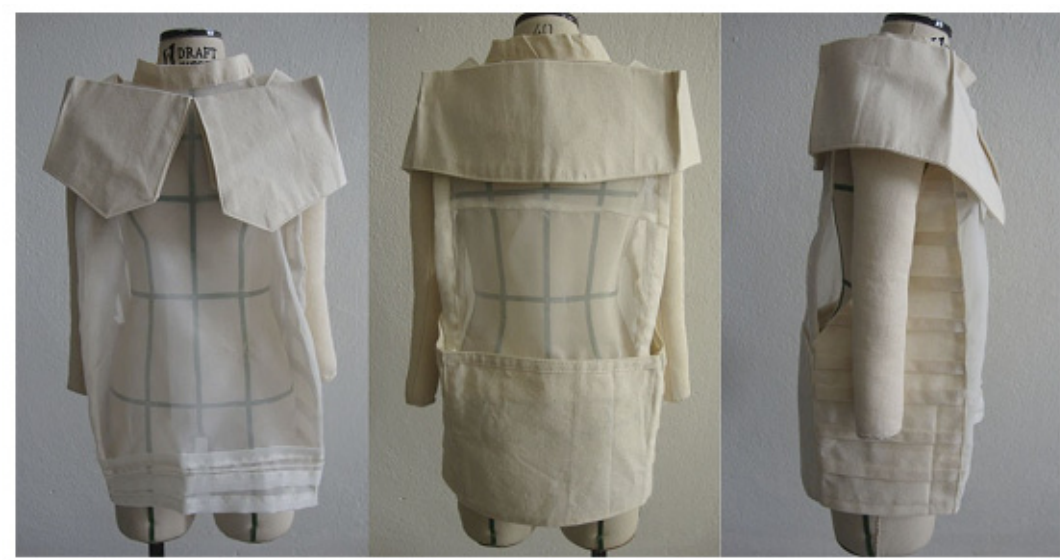

Figura 6- Exemplo de resoluções de confecção

Fonte: Própria (2011)

As pregas elaboradas no algodão estão dispostas nas laterais do modelo para enrijecêlas, além de evidenciar a forma do retângulo, ao promover o afastamento entre as partes frontal e dorsal. Em termos de resultado estético, tal solução construtiva confere relevância ao plano lateral. Frente e costas do produto, confeccionadas em voil, recebem a aplicação de pregas e nervuras nas barras, que se tornam mais rígidas para conferir estabilidade à estrutura, quando unidas com as laterais. A gola-manga removível que se apóia nos ombros e sobrepõe o modelo descrito, contribui para enfatizar a silhueta retangular proposta.

O produto concebido pelas alunas Renata Secco Gomes dos Santos e Mariana Luiza Zirondi é fruto de um processo de desenvolvimento de caráter essencialmente exploratório no qual a vivência e o aprendizado com as experimentações conduzem à identificação da melhor solução. Após a geração de inúmeras alternativas, o franzido é selecionado como recurso construtivo mais apropriado para adequar o material ao volume necessário para configurar a silhueta trapezoidal. Inicialmente aplicou-se o franzido em toda a extensão do voil, porém, devido à ineficiência de se trabalhar em grande escala, optou-se pela modulação. A elaboração de pequenos módulos retangulares $(6,0 \mathrm{~cm} \times 4,5 \mathrm{~cm})$, unidos conforme mostrado abaixo, facilitou o manuseio do tecido, permitiu a redução do consumo de material e o aproveitamento de retalhos das experimentações iniciais. A construção modular foi opção fundamental para a eficácia do processo de configuração e determinante no resultado final do produto, ilustrado na figura 7.


Figura 7- Exemplo de resoluções de confecção

Fonte: Própria (2011) 
Estratégias Construtivas para a Configuração do Produto de Moda

O franzido também é um dos recursos utilizados para construir a silhueta circular proposta pelas alunas Timeni Andrade Gonçalves e Thaina de Oliveira Gonçalves. O emprego do franzido, combinado com pequenas pregas e torções fixadas por meio da costura, possibilita a criação de pontos com maior acúmulo de tecido, gerando volumes em áreas localizadas, conforme desejado. Para reproduzir o formato do círculo nas dimensões previstas, foi preciso estudar a relação entre a quantidade de torções aplicada, o distanciamento mantido entre elas e o volume gerado pela intervenção. Além disso, cada uma das possibilidades gera um resultado estético distinto, aspecto igualmente importante, que exerce influência na escolha da melhor solução. $O$ esquema construtivo que ilustra tais relações está representado na figura 8 , que também mostra o produto final.
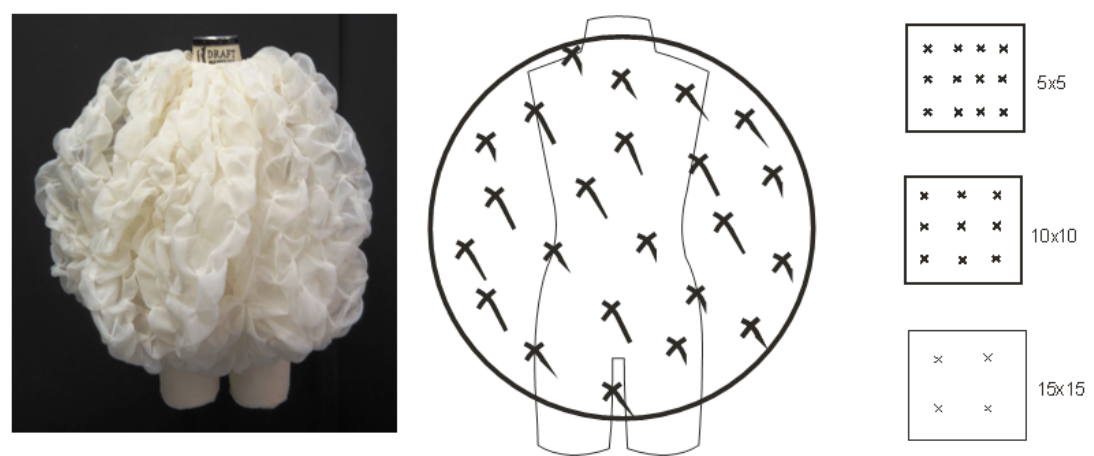

Figura 8- Exemplo de resoluções de confecção

Fonte: Própria (2011)

O produto desenvolvido pela aluna Andréia Cristina de Paula Avanzi (figura 9), adota a articulação de planos como recurso para a construção da silhueta trapezoidal. Totalmente confeccionada em voil, a proposta parte da união de dois planos com larguras diferentes, que quando unidos pelas laterais, gera um volume que é acarretado justamente pela diferença entre as dimensões, na tentativa do maior se ajustar aos contornos do menor. Na composição do produto mostrado na figura 9, esta estrutura formada pelos dois planos é reproduzida dez vezes, e todas elas são fixadas a uma base trapezoidal, dividida verticalmente em 10 partes retangulares, gerando novos volumes, que se articulam ao redor do corpo/suporte. A solução empregada permite diferentes configurações: para reproduzir a silhueta proposta utiliza-se um cinto, que ao comprimir todos os planos logo abaixo do busto, faz com que a estrutura se abra na extremidade configurando um trapézio; se adaptar um mecanismo de ajuste na barra, por sua vez, o formato assume contornos arredondados; se os planos ficam soltos, a silhueta também se altera tornando-se mais esguia.
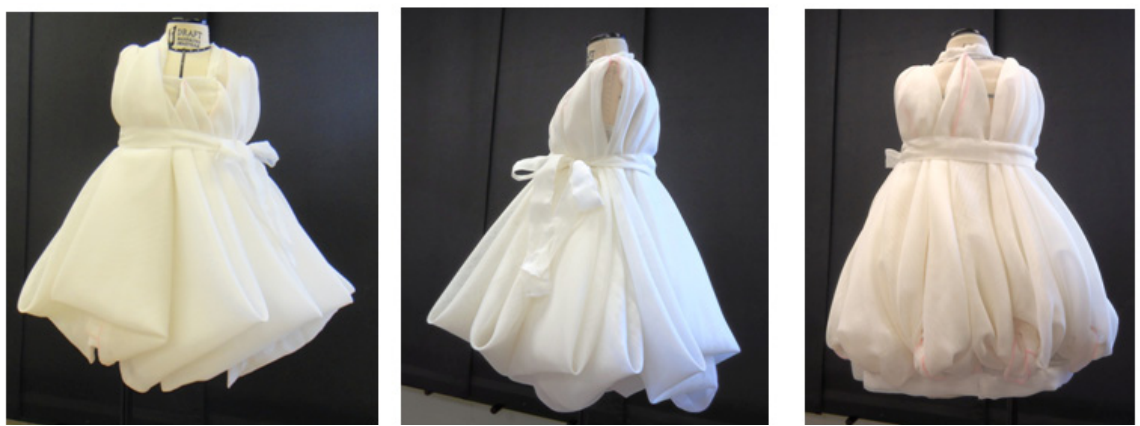

Figura 9- Exemplo de articulação de planos

Fonte: Própria (2011) 


\section{Discussão}

A observação criteriosa do processo de concepção e materialização dos produtos e a análise dos resultados obtidos no contexto da atividade projetual proposta, acima descrita, permitem a identificação e discussão de aspectos importantes para o desenvolvimento da presente pesquisa.

Determinadas intervenções aplicadas às superfícies mostram-se capazes de conferir grande flexibilidade aos têxteis, alterando a sua condição de vinculação ao corpo, mesmo se tratando de tecidos planos. Tal recurso propicia o estiramento do material, facilitando, portanto, a adaptação do produto a vários corpos. Com relação ao efeito tridimensional criado nas superfícies, são percebidos de modos diferentes de um lado e de outro do tecido, isto é, direito e avesso apresentam composições distintas, ampliando, assim, as possibilidades de uso do produto. Outras intervenções, como aquelas que aparentemente provocam um defeito no material, a exemplo de um fio puxado, podem gerar interessantes efeitos estéticos: desde uma listra, ocasionada pela retirada total do fio, até mesmo um franzido proporcionado pelo deslizamento do têxtil sobre o próprio fio puxado e não retirado.

Cabe afirmar que as intervenções nas superfícies podem agregar extremo valor aos materiais têxteis, especialmente naqueles considerados de baixo custo, como o voil, permitindo sua utilização para outras finalidades, além daquelas geralmente conhecidas. De modo geral, o voil é empregado na confecção de forros de cortina.

O mesmo elemento estruturante aplicado a materiais têxteis idênticos pode gerar resultados diferentes dependendo da estratégia construtiva adotada. A entretela, estrutura independente empregada em dois dos produtos acima descritos, ilustra tal condição. Em uma das situações, é descartada por alterar as características específicas do material e comprometer o resultado estético; em outra, o efeito obtido é aceitável, mesmo alterando os aspectos de transparência e leveza, porque a proposta construtiva considera outros elementos que, combinados, geram uma composição integrada e equilibrada.

Outro exemplo refere-se ao uso da barbatana. Quando usada para estruturar um dos produtos, é rejeitada por não oferecer a sustentação necessária; em outra proposta ela é empregada exatamente da mesma forma, no entanto, aplica-se também um outro elemento - no caso, o elástico - que complementa a sua função de suporte e confere ao produto a configuração requerida.

Quando a criação e a materialização são praticadas de modo simultâneo, muitas vezes o pensamento construtivo se desenvolve vinculado aos aspectos estéticos determinantes do produto. As propostas que abordam as resoluções de confecção, contemplam tal condição: pregas aplicadas nas laterais promovem a integração dos planos frontal e dorsal da vestimenta, conferem relevância formal a esta face do produto, além de enrijecê-la para dar sustentação à estrutura; em outro exemplo, a estratégia construtiva integra franzido, prega e torção, elementos que geram diferentes resultados estruturais e estéticos, dependendo da maneira como são combinados. Quando se trata de articulação de planos, as possibilidades que se apresentam são ainda maiores, pois as uniões entre planos podem ser fixas ou removíveis, permitindo inúmeras variações morfológicas, sempre vinculadas às soluções funcionais e estruturais.

\section{Considerações finais}


Estratégias Construtivas para a Configuração do Produto de Moda

É pertinente afirmar que o pensamento construtivo aliado às técnicas de modelagem viabilizam as estruturas.

Neste sentido, o desenvolvimento de produtos a partir de novos aplicativos de construção instiga a reflexão acerca dos processos de modelagem e montagem e remete a uma quebra de paradigma no que se refere às relações existentes entre materiais têxteis e suas aplicações.

Ao propor a aplicação dos diversos recursos construtivos às estruturas têxteis, cria-se a possibilidade de não só utilizar os materiais se apropriando de suas características intrínsecas, mas também novos caminhos se abrem para manipular seu aspecto e caimento. Seja por meio da inserção de um elemento externo à estrutura - o que remete a conceitos de sustentação - seja pela intervenção na sua superfície, ambos permitindo a utilização e o aproveitamento para outros fins.

Assim, um material leve e fluido pode se prestar também a silhuetas geométricas, mais rígidas, e não só a aderentes. Isto envolve processo criativo e gera inovação, incitando a novas concepções, em especial quando se vincula o desenvolvimento às técnicas da modelagem tridimensional.

\section{Notas}

${ }^{1}$ Texto baseado nos resultados apresentados e discutidos na dissertação de mestrado da autora.

2 Materia "Exposição de alunos de Design de Moda movimenta o Calçadão". Disponível em: http://www. uel.br/com/agenciaueldenoticias/index.php?arq=ARQ_not\&FWS_Ano_Edicao=1\&FWS_N_Edicao=1\&FWS_ Cod_Categoria=2\&FWS_N_Texto=12152.

\section{Referências}

ALDRICH, Winifred. Fabric, form and flat pattern cutting. New York: Blackwell, 2007.

CASTRO, Lucia Mors de. Patternmaking in fashion step by step. Koln: Evergreen, 2010.

CROSS, Nigel. From a design science to a design discipline: understanding designerly ways of knowing and thinking. In MICHEL, Ralf (Ed.). Design research now: essays and selected projects. Basel: Bierkhäuser Verlag, 2007. p.41-54.

HODGE, Brooke. Skin + bones: parallel practices in fashion and architecture. Londres: Thames \& Hudson, 2008.

MARTIN, Marcarena San. Field guide: how to be a fashion designer. Beverly: Rockport, 2009.

SALTZMAN, Andrea. El cuerpo diseñado: sobre la forma en el proyecto de la vestimenta. Buenos Aires: Paidós, 2004.

SALTZMAN, Andrea. O design vivo. In: PIRES, Dorotéia Baduy (Org.). Design de moda: olhares diversos. São Paulo: Estação das Letras e Cores, 2008. p.305-318.

SOUZA, Patrícia de Mello. A modelagem tridimensional como implemento do processo do desenvolvimento do produto de moda. 2006. Dissertação (Mestrado em Desenho Industrial) Faculdade de Arquitetura, Artes e Comunicação, Universidade Estadual Paulista, Bauru, 2006. 
Patrícia de Mello Souza; Marizilda dos Santos Menezes

SOUZA, Patrícia de Mello. A moulage, a inovação formal e a nova arquitetura do Corpo. In: PIRES, Dorotéia Baduy (Org.). Design de moda: olhares diversos. São Paulo: Estação das Letras e Cores, 2008. p.337-345.

SOUZA, Patrícia de Mello; MENEZES, Marizilda dos Santos. Aplicativos de construção no desenvolvimento do produto de moda. In: PASCHOARELLI, Luiz Carlos; MENEZES, Marizilda dos Santos (Orgs.). Design: questões de pesquisa. Rio de Janeiro: Rio Books, 2010.

VYZOVITI, Sophia. Supersurfaces: folding as a method of generating forms for architecture, products and fashion. Amsterdam: BIS, 2008. 